\title{
Natural Compounds Modulating Mitochondrial Functions
}

\author{
Lara Gibellini, ${ }^{1}$ Elena Bianchini, ${ }^{2}$ Sara De Biasi, ${ }^{1}$ Milena Nasi, ${ }^{1}$ \\ Andrea Cossarizza, ${ }^{1}$ and Marcello Pinti ${ }^{2}$ \\ ${ }^{1}$ Department of Surgery, Medicine, Dentistry and Morphological Sciences, University of Modena and Reggio Emilia, \\ Via G. Campi 287, 41125 Modena, Italy \\ ${ }^{2}$ Department of Life Sciences, University of Modena and Reggio Emilia, Via G. Campi 287, 41125 Modena, Italy
}

Correspondence should be addressed to Marcello Pinti; marcello.pinti@unimore.it

Received 11 May 2015; Accepted 11 June 2015

Academic Editor: Muriel Cuendet

Copyright (C) 2015 Lara Gibellini et al. This is an open access article distributed under the Creative Commons Attribution License, which permits unrestricted use, distribution, and reproduction in any medium, provided the original work is properly cited.

\begin{abstract}
Mitochondria are organelles responsible for several crucial cell functions, including respiration, oxidative phosphorylation, and regulation of apoptosis; they are also the main intracellular source of reactive oxygen species (ROS). In the last years, a particular interest has been devoted to studying the effects on mitochondria of natural compounds of vegetal origin, quercetin $(\mathrm{Qu})$, resveratrol (RSV), and curcumin (Cur) being the most studied molecules. All these natural compounds modulate mitochondrial functions by inhibiting organelle enzymes or metabolic pathways (such as oxidative phosphorylation), by altering the production of mitochondrial ROS and by modulating the activity of transcription factors which regulate the expression of mitochondrial proteins. While Qu displays both pro- and antioxidant activities, RSV and Cur are strong antioxidant, as they efficiently scavenge mitochondrial ROS and upregulate antioxidant transcriptional programmes in cells. All the three compounds display a proapoptotic activity, mediated by the capability to directly cause the release of cytochrome $\mathrm{c}$ from mitochondria or indirectly by upregulating the expression of proapoptotic proteins of $\mathrm{Bcl}-2$ family and downregulating antiapoptotic proteins. Interestingly, these effects are particularly evident on proliferating cancer cells and can have important therapeutic implications.
\end{abstract}

\section{Introduction}

Mitochondria are unique membrane-enclosed organelles found in eukaryotic cells; they are usually described as the "powerhouse" of the cell as they contain the molecular machinery that governs many distinct metabolic pathways taking place within these organelles, including (but not limited to) pyruvate oxidation, fatty acid $\beta$-oxidation, Krebs cycle, and oxidative phosphorylation (OXPHOS) [1]. Mitochondria importance is not limited to cell metabolism or regulation of bioenergetics pathways. Indeed, during the last decades, their role as master regulators controlling stress responses and cell death has emerged [2-4]. Furthermore, mitochondria are the main intracellular source of reactive oxygen species (ROS) [5]. The multiple functions of mitochondria have more and more underlined the great relevance of such organelle in biomedicine. Indeed, not only are they responsible for several genetic diseases, due to inherited mutations of mitochondrial DNA (mtDNA), but also they play a main role in the processes of inflammation, aging, cancerogenesis, and neurodegeneration [3, 6-11].

In the last decades, a particular interest has been devoted to studying the effects of natural compounds of vegetal origin (often referred to as phytochemicals, herbals, or phytocompounds) on human cells, as these compounds are often taken with the diet at biologically active concentrations and constitute fundamental components of traditional medicine of several countries [8, 12-18]. Many of these compounds turned out to exert their functions by affecting mitochondrial functions, either directly, by inhibiting specific enzymes, or indirectly, by modulating signal from or to mitochondria [1923].

In this review, we will discuss recent discoveries concerning the effects of natural compounds on mitochondria, with a major emphasis on resveratrol (RSV), the flavonoid quercetin $(\mathrm{Qu})$, and curcumin (Cur) derivatives, probably the 
<smiles>Oc1ccc(/C=C/c2cc(O)cc(O)c2)cc1</smiles>

Quercetin $\left(3,3^{\prime}, 5^{\prime}, 5,7\right.$-penta-hydroxyflavone)<smiles>O=c1c(O)c(-c2ccc(O)c(O)c2)oc2cc(O)cc(O)c12</smiles>

Resveratrol (3,5,4-trihydroxystilbene)<smiles>COc1cc(/C=C/C(=O)CC(=O)/C=C/c2ccc(O)c(OC)c2)ccc1O</smiles>

Curcumin (1,7-bis(4-hydroxy-3-

methoxyphenyl)-1,6-heptadiene-3,5-dione)

FIGURE 1: Chemical structure of quercetin $(\mathrm{Qu})$, resveratrol (RSV), and curcumin (Cur).

most studied plant-derived natural compounds (Figure 1). Resveratrol (3,5,4-trihydroxystilbene) is a stilbenoid naturally produced by several plants in response to environmental stress or injury and present in many fresh fruits (including grapes, blueberries, and raspberries) or fruit-derived foods. Quercetin $\left(3,3^{\prime}, 4^{\prime}, 5,7\right.$-pentahydroxyflavone) is a main dietary flavonoid, present in vegetables, fruits, seeds, nuts, tea, and red wine $[11,24,25]$. Curcumin (1,7-bis(4-hydroxy3-methoxyphenyl)-1,6-heptadiene-3,5-dione) is a diarylheptanoid derived from the rhizome of Curcuma longa, which exhibits cancer growth inhibition both in vitro and in vivo $[26,27]$, by suppressing cell proliferation and inhibiting tumourigenesis [28-33].

\section{Mitochondria, Oxidative Phosphorylation, and Natural Compounds}

Mitochondria are the organelle where cell respiration, OXPHOS, and synthesis of most cellular ATP take place. Since these metabolic processes involve dozens of proteins or protein complexes, effects of phytochemicals on them are very complex and often difficult to interpret and are subject of intensive investigation. ATP is synthesized in mitochondria by F0F1 ATP synthase, a multimeric complex consisting of the catalytic F1 sector (a3b3cde) and the trans-membrane proton pathway, the F0 sector (ab2c10). Several phytochemicals, including piceatannol, Qu, RSV, Cur, (-)epigallocatechin gallate, (-)epicatechin gallate, curcumin, genistein, or biochanin, are able to inhibit F0F1 ATPase, both in mitochondria of mammalian cells or in prokaryotic cells [19, 22, 23, 34, 35].
2.1. Effects of Quercetin on Oxidative Phosphorylation. The effects of Qu on mitochondrial biochemical pathways are of particular interest, since Qu can specifically accumulate in these organelles [36]. More than 40 years ago it was shown that $\mathrm{Qu}$ inhibits mitochondrial ATP synthase, similarly to well-known inhibitors of mitochondrial electron transport. Moreover, Qu strongly affects the succinate oxidase as well as the NADH oxidase activities but has no effect on OXPHOS in submitochondrial particles [37]. More recently, it has been shown that $\mathrm{Qu}$ can uncouple OXPHOS at concentrations as high as $30 \mu \mathrm{M}$. Interestingly, at concentration $>50 \mu \mathrm{M}$, $\mathrm{Qu}$ stimulates oxygen consumption, inhibits OXPHOS, decreases mitochondrial membrane potential, and causes $\mathrm{Ca}^{2+}$ release $[38,39]$; the uncoupling effect, with a dosedependent stimulation of State 2 respiration rate, has also been observed in rat heart mitochondria [40].

2.2. Effects of Resveratrol on Oxidative Phosphorylation. Resveratrol improves mitochondrial function by inducing the expression of genes for oxidative phosphorylation and mitochondrial biogenesis; this effect is mediated by a decrease in the acetylation of PGC-lalpha-one of the master regulators of mitochondrial biogenesis - and by the subsequent increase in its functional activity [41]. Several studies performed in vivo on rats further demonstrated the beneficial effect of RSV on mitochondria. In particular, dietary supplementation with RSV causes an amelioration of several mitochondrial functions (oxygen consumption, activity of respiratory enzymes, and activity of lipid-oxidizing enzymes) [42-44]. It must be noted, however, that in mitochondria isolated from rat brain RSV inhibits the mitochondrial F0F1-ATPase activity in a concentration-dependent manner, in the range of $0.7-70 \mu \mathrm{m}$, suggesting that RSV can also impair mitochondrial metabolic pathways [23].

2.3. Effects of Curcumin on Oxidative Phosphorylation. In isolated mitochondria from rat liver, Cur acts as a protonophoric uncoupler [45]. In this model, Cur decreases ATP biosynthesis, activates F0F1-ATPase in a dose-dependent manner (a common feature of protonophoric uncouplers), and inhibits respiration at concentrations $>50 \mu \mathrm{M}$ [45]. However, it is interesting to note that Cur inhibits the F0F1-ATPase in rat brain mitochondria, indicating that different-in this case, opposite-effects of this phytochemical can be observed in the same organelle from different tissues [23, 45]. A possible mechanism of this action has been elucidated in Escherichia coli, where Cur directly inhibits F1 ATPase activity by disrupting the beta subunit catalytic site conformational transitions $[22,34]$.

\section{Mitochondria, Reactive Oxygen Species, and Natural Compounds}

Quantitative date on isolated mitochondria indicates that up to $5 \%$ of oxygen consumption is due to superoxide anion $\left(\mathrm{O}_{2}{ }^{--}\right)$generation [46]. However, superoxide generation is heavily influenced by the cell type and by the respiration steady state; under physiologic conditions, the superoxide production is estimated to be about $0.1 \%$ of 
TABLE 1: Direct and indirect effects of Qu, RSV, and Cur on mitochondrial ROS.

\begin{tabular}{|c|c|c|c|c|c|}
\hline Molecule & $\begin{array}{c}\text { Effects on mitochondrial } \\
\text { ROS }\end{array}$ & Model used & Doses & $\begin{array}{l}\text { Time of } \\
\text { treatment }\end{array}$ & References \\
\hline \multicolumn{6}{|l|}{ Quercetin } \\
\hline \multirow[t]{2}{*}{ Direct effects } & Scavenging of $\mathrm{O}_{2}{ }^{\cdot-}$ & $\begin{array}{l}\text { Cell-free system; CHO } \\
\text { cells }\end{array}$ & $10-200 \mu \mathrm{M}$ & Up to 24 hours & [49] \\
\hline & Scavenging of $\mathrm{H}_{2} \mathrm{O}_{2}$ & $\begin{array}{l}\text { Cell-free system; CHO } \\
\text { cells }\end{array}$ & $10-200 \mu \mathrm{M}$ & Up to 24 hours & [49] \\
\hline $\begin{array}{l}\text { Direct effects as } \\
\text { prooxidant }\end{array}$ & $\begin{array}{c}\text { Production of } \\
\text { semiquinone radical and } \\
\text { Qu-quinone, which } \\
\text { depletes GSH }\end{array}$ & $\begin{array}{l}\text { Cell-free system; CHO, } \\
\text { U937, THP-1, HL-60, } \\
\text { and NB4 cells }\end{array}$ & $10-200 \mu \mathrm{M}$ & Up to 24 hours & {$[49,51-53]$} \\
\hline $\begin{array}{l}\text { Indirect effects on } \\
\text { antioxidant } \\
\text { systems }\end{array}$ & Inhibition of TrxR & $\begin{array}{l}\text { Cell-free system; } \\
\text { A549 cells }\end{array}$ & $25-100 \mu \mathrm{M}$ & 24 hours & {$[56]$} \\
\hline \multicolumn{6}{|l|}{ Resveratrol } \\
\hline \multirow{3}{*}{$\begin{array}{l}\text { Direct effects as } \\
\text { antioxidant }\end{array}$} & Scavenging of $\mathrm{O}_{2}{ }^{\cdot-}$ & $\begin{array}{l}\text { U937, K562, HepG2 } \\
\text { MCF-7, NHEK cells; } \\
\text { RAW 264.7, JB6 cells; } \\
\text { Wistar-Kyoto rats }\end{array}$ & $0-150 \mu \mathrm{M}$ & Up to 48 hours & [65-67] \\
\hline & Scavenging of ${ }^{\bullet} \mathrm{OH}$ & $\begin{array}{l}\text { U937, K562 HepG2 } \\
\text { MCF-7, NHEK cells }\end{array}$ & $0-150 \mu \mathrm{M}$ & Up to 48 hours & {$[65,66]$} \\
\hline & Scavenging of $\mathrm{H}_{2} \mathrm{O}_{2}$ & $\begin{array}{l}\text { N9 microglial cells, C6 } \\
\text { astroglial cells }\end{array}$ & $25-100 \mu \mathrm{M}$ & $0-600$ secs & {$[64]$} \\
\hline \multirow{3}{*}{$\begin{array}{l}\text { Indirect effects on } \\
\text { antioxidant } \\
\text { systems }\end{array}$} & $\begin{array}{l}\text { Upregulates glutathione } \\
\text { peroxidase and catalase }\end{array}$ & $\begin{array}{l}\text { Rat coronary endothelial } \\
\text { cells }\end{array}$ & $1-100 \mu \mathrm{M}$ & 48 hours & {$[76]$} \\
\hline & Upregulates MnSOD & $\begin{array}{l}\text { Human coronary } \\
\text { endothelial cells }\end{array}$ & $1-10 \mu \mathrm{M}$ & 48 hours & {$[77]$} \\
\hline & $\begin{array}{l}\text { Activates Nrf2 mediated } \\
\text { antioxidant response }\end{array}$ & $\begin{array}{c}\text { Normal human } \\
\text { epidermal keratinocytes }\end{array}$ & $20-100 \mu \mathrm{M}$ & 16 hours & {$[73]$} \\
\hline \multicolumn{6}{|l|}{ Curcumin } \\
\hline \multirow{6}{*}{$\begin{array}{l}\text { Direct effects as } \\
\text { antioxidant }\end{array}$} & Scavenging of $\mathrm{O}_{2}{ }^{--}$ & $\begin{array}{l}\text { Cell-free system; heart } \\
\text { homogenate from } \\
\text { Wistar rats }\end{array}$ & $0-200 \mu \mathrm{M}$ & 48 hours & {$[81,82]$} \\
\hline & Scavenging of ${ }^{\bullet} \mathrm{OH}$ & Rat L-6 myoblasts & $0-4 \mu \mathrm{M}$ & 30 mins & {$[84]$} \\
\hline & Scavenging of $\mathrm{H}_{2} \mathrm{O}_{2}$ & $\begin{array}{c}\text { Cell-free system; Rat L-6 } \\
\text { myoblasts }\end{array}$ & $\begin{array}{c}15-45 \mu \mathrm{g} / \mathrm{mL} \\
0-4 \mu \mathrm{M}\end{array}$ & 30 mins & {$[82,84]$} \\
\hline & Scavenging of $\mathrm{ONOO}^{-}$ & & & & [85] \\
\hline & Scavenging of $\mathrm{NO}^{\circ}$ & $\begin{array}{c}\text { Cell-free system; } \\
\text { G108-15 } \\
\text { neuroblastoma-glioma } \\
\text { cells }\end{array}$ & $1-25 \mu \mathrm{M}$ & & {$[86]$} \\
\hline & Scavenging of ROO ${ }^{\circ}$ & Rat L-6 myoblasts & $0-4 \mu \mathrm{M}$ & 30 mins & {$[84]$} \\
\hline \multirow{2}{*}{$\begin{array}{l}\text { Indirect effects on } \\
\text { antioxidant } \\
\text { systems }\end{array}$} & $\begin{array}{c}\text { Upregulation of } \\
\text { antioxidant enzymes } \\
\text { (SOD, CAT, and HO-1) }\end{array}$ & $\begin{array}{l}\text { C6 rat glioma cells; rat } \\
\text { cerebellar granule } \\
\text { neurons; ECV304 } \\
\text { human endothelial cells }\end{array}$ & $0-100 \mu \mathrm{M}$ & Up to 48 hours & [87-89] \\
\hline & $\begin{array}{l}\text { Replenishment of } \\
\text { glutathione pool via } \\
\text { upregulation of GR, } \\
\text { GPx, and GST }\end{array}$ & Chick liver & $74 \mathrm{mg} / \mathrm{kg}$ & Up to 21 days & {$[90]$} \\
\hline
\end{tabular}

the respiratory rate [47]. Mitochondrial ROS are not just dangerous molecules: they also regulate several cell processes, including (but not limited to) apoptosis, autophagy, and unfolded protein response [5]. Quercetin, resveratrol, and curcumin can modulate in several ways the levels of different
ROS and other free radicals within the cell (Table 1). Nevertheless, it must be noted that the capability of phytochemicals to directly scavenge ROS is probably not very relevant in vivo as, at the concentrations that they can reach within the cell, their scavenging effect is marginal if compared with 
detoxifying systems such as GSH. However, these compounds can indirectly exert an antioxidant activity by modulating antioxidant cell response-an effect that is much more important in vivo.

\subsection{Effects of Quercetin on Mitochondrial ROS. Quercetin can} exert both antioxidant and prooxidant activity [11]. Because of the high number of hydroxyl groups and conjugated $\pi$ orbitals, Qu can efficiently scavenge mitochondrial ROS such as $\mathrm{O}_{2}{ }^{--}$and hydrogen peroxide $\left(\mathrm{H}_{2} \mathrm{O}_{2}\right)$ [48]. The reaction of $\mathrm{Qu}$ with $\mathrm{O}_{2}{ }^{--}$leads to the generation of the semiquinone radical and $\mathrm{H}_{2} \mathrm{O}_{2}$. Then, $\mathrm{Qu}$ reacts with $\mathrm{H}_{2} \mathrm{O}_{2}$ and decreases its levels in the presence of peroxidases [49]. During the same process, potentially harmful reactive oxidation products can also be formed: semiquinone radical, the first product of $\mathrm{Qu}$, is unstable and undergoes a second oxidation reaction that produces $\mathrm{Qu}$-quinone, a molecule capable of damaging DNA and causing lipid peroxidation [50].

$\mathrm{Qu}$ can alter ROS metabolism by directly lowering the intracellular pool of GSH [51-53]. Indeed, Qu reacts with ROS and forms semiquinone and quinone radicals [49], which are highly reactive toward thiols, and preferentially react with GSH [54]. Thus, Qu depletes GSH in a concentration-dependent manner [54]. This phenomenon has been observed not only in cell lines, but also ex vivo: in isolated rat liver nuclei, $\mathrm{Qu}$ reduces, in a dose-dependent manner, nuclear GSH content [55]. Finally, Qu can indirectly affect intracellular ROS levels by inhibiting enzymes related with antioxidant activity, such as thioredoxin reductase and the glutathione S-transferase (GST) activity [55, 56].

Qu can also modulate the antioxidant pathway triggered by nuclear factor-erythroid 2 related factor 2 ( Nrf2, a master regulator of antioxidant response). In normal conditions, Nrf2 is bound to Keap-1, which represses its activity by targeting it for ubiquitin degradation pathway [57, 58]. In the presence of oxidative stress, NRf2 is released from Keap1 and translocates into the nucleus, where it activates the antioxidant transcriptional programme; this leads to the upregulation of genes involved, at least in part, in the increase of cell glutathione content. In HepG 2 cells, $\mathrm{Qu}$ at the dose of $50 \mathrm{uM}$ is able to rapidly (within 60 minutes) induce the phosphorylation and translocation into the nucleus of Nrf2, to later inhibit both effects. This activation is correlated with the activation of the GSH-related antioxidant/detoxifying enzymes [59]. In longer exposition, Qu causes the increase of Nrf2 levels by increasing its transcription, and by stabilizing the protein through the inhibition of its ubiquitination and degradation. Furthermore, $\mathrm{Qu}$ is able to decrease the levels of Keap-1, the inhibitor of Nrf2, at the posttranslational level. Thus, the higher levels of Nrf2 determine an increase in the activity of the Nrf2-dependent antioxidant-responsive element/electrophile-responsive element (ARE/EpRE) and the transcription of a series of genes involved in antioxidant response, such as the NADPH:quinone oxidoreductase (NQO1) [60].

Studies performed in vivo on rats have shown that $\mathrm{Qu}$ can have a protecting role in ischemia/reperfusion injury in different brain and heart cell types, by attenuating the cytotoxic effects of ROS and decreasing mitochondriamediated apoptosis [61-63].

3.2. Effects of Resveratrol on Mitochondrial ROS. The antioxidant activity of RSV has been shown by a considerable number of reports and observed in transformed cells of different origin, as well as in nontransformed cells. Resveratrol decreases ROS in mitochondria as it acts as a potent scavenger of superoxide anion, hydrogen peroxide, and hydroxyl radical $\left(\mathrm{OH}^{\circ}\right)$, inhibits lipid peroxidation, and helps to replenish glutathione levels [64-67]; the antioxidant activity of RSV results in a cytoprotective effect on several cell types, including (but not limited to) keratinocytes, cardiomyocytes, adipocytes, neurons, and brain tissue [67-74].

Resveratrol can also exert its antioxidant activity in an indirect manner, by modulating the expression of mitochondrial proteins or by increasing the expression of ROS scavenging enzymes. As in the case of Qu, RSV is able, in a dosedependent manner, to activate the antioxidant pathway triggered by $\mathrm{Nrf} 2$ in keratinocytes and in cultured coronary arterial endothelial cells $[73,75]$. Also in this case, Nrf2 activation determines a higher ARE activity and a significant upregulation of Nrf2 target genes, such as NQO1 and HO-1 [75].

In endothelial cells, RSV reduces mitochondrial ROS generation by increasing SIRT3 levels within the mitochondria, which in turns leads to the to increased complex I activity and ATP synthesis through the upregulation of mitochondrial proteins ATP6, CO1, Cytb, ND2, and ND5 [74]. Concerning scavenging enzymes, RSV is able to upregulate glutathione peroxidase, catalase [76], and MnSOD [77] expression in endothelial cells, in a SIRT1-dependent manner [77, 78].

3.3. Effects of Curcumin on Mitochondrial ROS. Curcumin displays antioxidant and cytoprotective effects on several cell types, including hepatoma cell lines, retinal epithelial cells, astrocytes, and spinal cord astrocytes [71, 78-80]. Curcumin exerts its antioxidant properties through direct and indirect mechanisms. Indeed, Cur is an effective scavenger of free radicals such as hydroxyl radical $\left(\mathrm{OH}^{\circ}\right), \mathrm{O}_{2}{ }^{-}$, nitric oxide (NO), $\mathrm{H}_{2} \mathrm{O}_{2}$, and peroxynitrite [81-86]. Concerning indirect mechanisms, Cur is able to upregulate cytoprotective cell response by modulating the expression of genes encoding antioxidant proteins, such as superoxide dismutase (SOD), catalase (CAT), heme oxygenase-1 (HO-1), or proteins that replenish the glutathione pool such as glutathione reductase (GR), glutathione peroxidase (GPx), and GST [87-90]. As in the case of RSV, the upregulation of these genes is induced by the Cur-mediated transactivation of Nrf 2 and has been demonstrated in several in vitro cell models [91, 92] as well as in vivo ones $[93,94]$. The antioxidant and cytoprotective effects of Cur have been proven to be beneficial also in vivo. Similarly to $\mathrm{Qu}$, Cur protects cardiac cells from ischemia reperfusion (I/R) damage by reducing oxidative stress and by helping cells to maintain intact mitochondrial functions [81]; in an in vivo model of chronic kidney disease, Cur displayed cardioprotective effects that were mediated by diminished ROS production and by the maintenance of mitochondrial functions, such as OXPHOS $[95,96]$. 
Cur can also have a cytoprotective effect against toxic compounds able to generate ROS and to cause lipid peroxidation and DNA damage, such as potassium dichromate $\left(\mathrm{K}_{2} \mathrm{Cr}_{2} \mathrm{O}_{7}\right)$. Indeed, several studies have shown that $\mathrm{Cu}$ pretreatment has a protective role against toxicity of $\mathrm{K}_{2} \mathrm{Cr}_{2} \mathrm{O}_{7}$ for kidney, liver, and male reproductive system [97-99]. In vivo, Cur prevents the decrease in body weight caused by $\mathrm{K}_{2} \mathrm{Cr}_{2} \mathrm{O}_{7}$ and increases liver weight and liver/body ratio and exerts a protective effect against oxidative damage to liver tissue, by preventing the decrease of hepatic antioxidant enzymes caused by $\mathrm{K}_{2} \mathrm{Cr}_{2} \mathrm{O}_{7}$. These effects appear to be mediated by a protective effect on mitochondria. Indeed, studies on isolated organelles showed that Cur reduces mitochondrial dysfunction by preventing the reduction of complex I activity and the opening of the PTP induced by $\mathrm{K}_{2} \mathrm{Cr}_{2} \mathrm{O}_{7}$. This preventive activity blocks the release of cyt $\mathrm{c}$, likely inhibiting mitochondrial-induced apoptosis [99].

A similar, protective effect has been demonstrated in rats treated with indomethacin, a potent ROS inducer: administration of Cur prevented oxidative stress and maintained mitochondrial functions in cells from colon [100].

\section{Effects of Natural Compounds on Mitochondrial-Mediated Apoptosis and Mitophagy and on Mitochondrial Biogenesis}

In the last twenty years, the effects of natural compounds on apoptosis have been subject of huge investigations, mainly aimed at identifying molecules able to selectively cause death of cancer cells [101]. However, it must be noted that the results of this type of studies are often difficult to interpret, because of the enormous variety of in vitro and in vivo model used, the dose dependency of the effects of many compounds, and the capability of the same compounds to exert a prosurvival effect in cancer cells, by favouring mitochondrial biogenesis and cell proliferation. The systematic reanalysis of this plethora of studies goes further beyond the purpose of this review; in this paragraph, we will summarize the direct and indirect mechanisms by which QU, RSV, and Cur modulate mitochondriamediated apoptosis (summarized in Table 2) or, conversely, increase mitochondrial biogenesis.

4.1. Quercetin, Mitochondrial Biogenesis, and Apoptosis. Data concerning the effects of $\mathrm{Qu}$ on mitochondrial biogenesis are quite controversial. In HepG2 cells, Qu induces mitochondrial biogenesis through activation of HO-1 [102]. Conversely, in vivo data obtained on mice or rats gave opposite results, depending on the experimental design and the cell type taken into account. Higher expression of PPAR-gamma, cytochrome c (cyt c) oxidase, and citrate synthase were noted; furthermore, increased mitochondrial biogenesis was accompanied by higher levels of mtDNA [103]. Conversely, other authors have shown that muscle mitochondrial biogenesis should be attributed exclusively to exercise and that $\mathrm{Qu}$ supplementation in the diet had negligible effect on mitochondria in mice fed with high-fat diet [104]. The combination of oral $\mathrm{Qu}$ supplementation and exercise has been shown to prevent brain mitochondrial biogenesis [105].
The capability of Qu to trigger apoptosis via mitochondrial pathway has been shown in a variety of cell models [38, 106-111]. It is particularly interesting to observe that, in some cases, Qu causes cell death in cancer cells, but not in the parental, nonmalignant cells [112].

$\mathrm{Qu}$ is able to trigger mitochondria-mediated apoptosis both by direct and indirect mechanisms [11]. Concerning direct mechanisms, $\mathrm{Qu}$ induces loss of mitochondrial membrane potential (MMP), release of cytochrome $c$ from mitochondria, and the subsequent activation of caspase- 3 and caspase-7 $[106,108]$. Experiments on isolated mitochondria from rat liver have shown that $\mathrm{Qu}$ causes the release of cyt c by inhibiting adenine nucleotide translocase (ANT), which in turn determines the opening of the permeability transition pore (PTP), through a cyclosporin A insensitive mechanism [38]. In several cell models, the capability to induce apoptosis appears to be correlated with the capability of $\mathrm{Qu}$ to deplete GSH, an event that precedes loss of MMP, phosphatidylserine exposure, decrease of mitochondrial mass, and subsequent cell death $[11,112]$.

$\mathrm{Qu}$ can also favour apoptosis by modulating the expression of pro- and antiapoptotic proteins belonging to the $\mathrm{Bcl}-$ 2 family. In particular, $\mathrm{Qu}$ upregulates Bax and Bak and downregulates $\mathrm{Bcl}-2$ and $\mathrm{Bcl}-\mathrm{xL}[108,110]$, thus determining the multimerization of Bax to the mitochondrial membrane.

Another indirect mechanism by which $\mathrm{Qu}$ exerts a proapoptotic activity is the generation of ROS. As stated above, $\mathrm{Qu}$ can increase intracellular ROS levels, as Qu radicals can be formed after peroxidase-catalyzed oxidation in order to scavenge reactive peroxyl radicals [113]. In some conditions, $\mathrm{Qu}$ generates enough ROS to trigger free radical-induced apoptosis, through the activation of the AMPK1/ASK1/p38 pathway [114]. Accordingly, the generation of ROS determines the subsequent activation of AMPKalphal and ASK1, which are accompanied by activation of $\mathrm{p} 38$ and recruitment of caspases [115-117].

4.2. Resveratrol, Mitochondrial Biogenesis, and Apoptosis. Several studies indicate that RSV can have some beneficial effects on mitochondrial biogenesis and activity [41]. In particular, it has been shown that RSV supplementation in the diet of rodents is associated with an increase in mtDNA content and of protein levels of mitochondrial transcription factor A (Tfam) and PGC- $1 \alpha$; this increase is mirrored by an increase in oxygen consumption and in the activity of respiratory and lipid-oxidizing mitochondrial enzymes [42-44, 118]. Concerning mitochondrial biogenesis, RSVstimulating effects are mediated by a mechanism involving three main actors, namely, PGCla, SIRT1, and AMPK [41, 119]. As mentioned above, SIRT1 is activated in cells exposed to RSV and other polyphenols, including flavonoids, butein, catechins, and Cur [120]. Whether RSV acts directly on SIRT1 or its action is indirect is still matter of debate. While some authors have shown that RSV can directly act on Sir2, the yeast ortholog of human SIRT1 in Saccharomyces cerevisiae, [121] others did not evidence any direct effect and ascribed the observed phenomenon to technical problems [122, 123]. Accumulating data now indicate that the effects on SIRT1 are mediated by AMPK activation. Finally, it must be noted that 


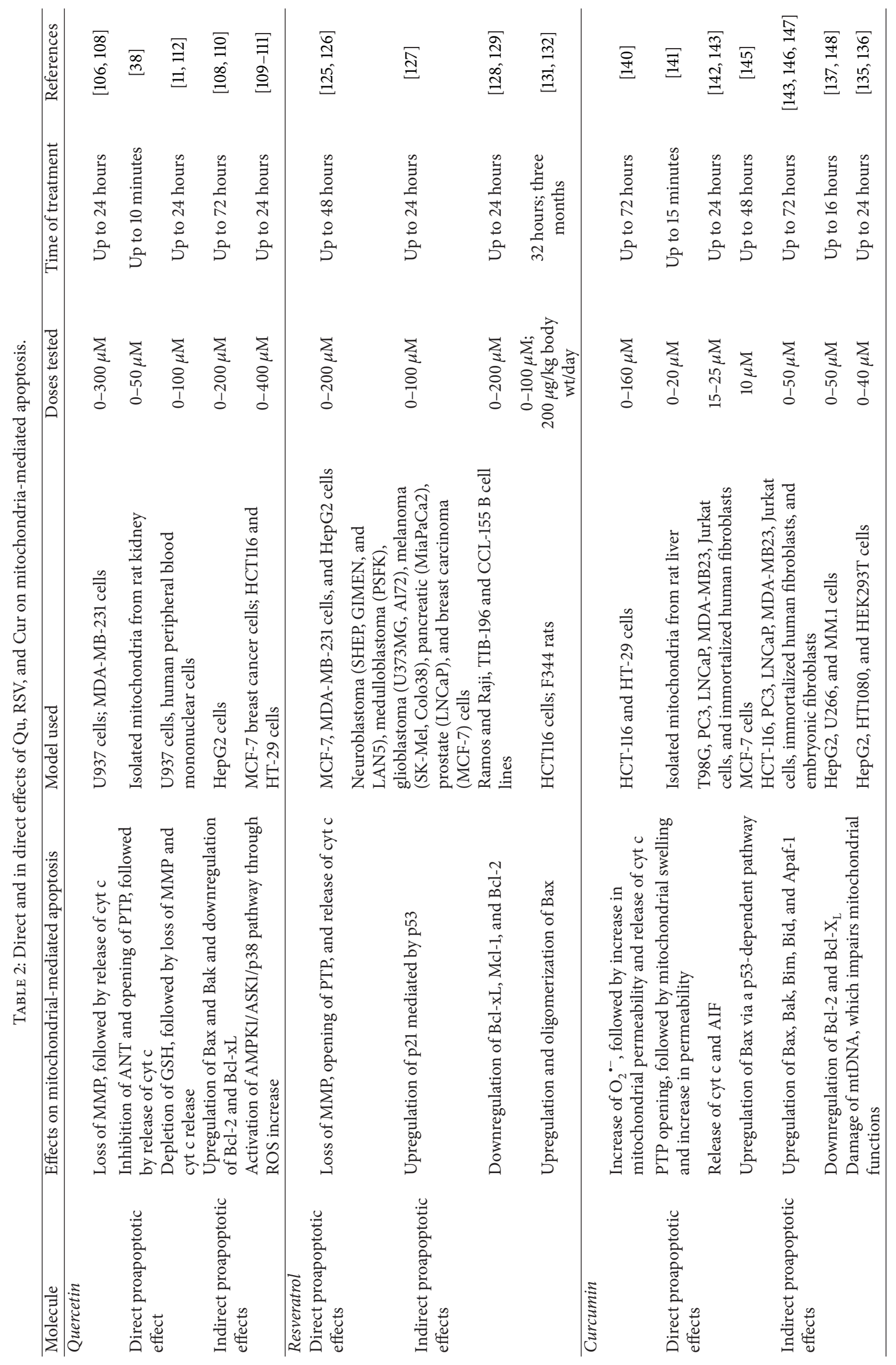


a recent study casted some doubts on the effects of RSV on mitochondrial biogenesis, at least in muscle cells [124].

RSV has the capability to induce apoptosis in different manners. At high concentration $(100 \mu \mathrm{M})$, RSV induces apoptosis in breast cancer cell lines [125], by provoking rapid depolarization of mitochondria, release of $\mathrm{Ca}^{2+}$ from the ER, followed by opening of PTP, release of cyt $c$, and activation of caspases; xenograft experiments further confirm that RSV treatment inhibits breast cancer growth [125]. The same effect has been observed in hepatocarcinoma cells [126]. RSV acts as an antagonist of antiapoptotic proteins, therefore favouring the induction of apoptosis in cancer cells. In particular, it induces the upregulation of p21 in a p53-independent manner, which in turn determines cell cycle arrest, depletion of the antiapoptotic protein survivin, and sensitization to TRAIL-mediated apoptosis [127]. RSV also suppresses the expression of the antiapoptotic proteins $\mathrm{Bcl}-\mathrm{xL}, \mathrm{Mcl}-1$, and Bcl-2 in different human cancer cell lines [128, 129]; in U937 cells, this effect is due to the suppression of constitutively active NF-kB, through RSV-mediated inhibition of IkB. The ectopic overexpression of Bcl-2 attenuates RSV proapoptotic effect, confirming the proapoptotic effect of this molecule through the downregulation of antiapoptotic genes [130]. Furthermore, RSV can favour apoptosis by increasing the expression of the proapoptotic protein Bax [131, 132] or by inducing oligomerization of Bax on mitochondria [133].

\subsection{Curcumin, Mitochondrial Biogenesis, and Apoptosis. Data} concerning Cur effects on mitochondrial biogenesis are scarce and mainly obtained by in vivo studies [134-137]. In hepatocytes isolated from rats, Cur treatment increases mtDNA copy number and upregulates transcriptional factors that regulate mitochondrial biogenesis, including $\mathrm{PGCl} \alpha$, Nrf1, and Tfam [134]. In vivo studies on rats subjected to $\mathrm{I} / \mathrm{R}$ injury further confirm that Cur increases mitochondrial biogenesis. Indeed, Cur pretreatment reverts the reduction in Nrf-1 and Tfam and in the number of mitochondria observed with $\mathrm{I} / \mathrm{R}$ and helps in reducing infarct volume and in maintaining neuron functionality, in a dose-dependent manner [138].

As mentioned above, the anticancer properties of Cur rely on its capacity to inhibit proliferation and induce cancer cell death. Many studies, performed on different human and murine cell types, indicate that Cur, like Qu and RSV, can have both proapoptotic and cytoprotective effects, depending on the dose or cell model used [139].

The mechanisms by which Cur induces cancer cell death are not clearly defined and are likely mediated by different pathways; nevertheless, the crucial role of mitochondriamediated apoptosis is well established in different cell models. At high concentration $(80 \mu \mathrm{M})$, Cur has a prooxidant activity, as it leads to increased levels of $\mathrm{O}_{2}^{-\bullet}$ and causes cell death in human colon cancer cells in a p53-independent manner [140]. The crucial role of mitochondria in Curmediated apoptosis has been demonstrated in isolated rat liver organelles: in this model, Cur induces an increase in the membrane permeability, resulting in swelling, loss of membrane potential, and inhibition of ATP synthesis; this effect is mediated by PTP opening [141]. In human glioblastoma cells, treatment with Cur at relatively low concentrations $(25-50 \mu \mathrm{M})$ causes release of $c y t c$ and AIF from mitochondria and subsequent cell death [142]; a similar effect has been observed in colorectal cancer cells [143]. Like other proapoptotic phytochemicals, Cur targets proliferative cells more efficiently than differentiated cells. For instance, Cur induces a rapid decrease in MMP and the release of cyt c followed by cell death in growing murine neural 2a (N2a) cells, but not in differentiated N2a cells [144].

The proapoptotic effects of Cur are also exerted in an indirect manner, through the upregulation of proapoptotic proteins located in mitochondria. In human breast cancer cells, Cur induces apoptosis via a p53-dependent pathway in which Bax is upregulated and renders cells more prone to apoptosis [145]. The crucial role of proapoptotic proteins of Bcl-2 family, such as Bax, Bak, Bim, and Bid in Cur-mediated apoptosis, has been further confirmed in other cell models $[143,146,147]$. In colorectal cancer cells, Cur sensitizes cells to apoptosis by upregulating of Bax, Bak, Bim, and Bid, as well as Apaf-1, and by inducing the oligomerization of Bax, which in turn favours the release of cyt $\mathrm{c}$ from mitochondria [143]. Cur can also favour apoptosis by downregulating antiapoptotic proteins, such as Bcl-2 [137], or by downregulating NFkappaB, which in turn determines the downregulation of both Bcl-2 and Bcl- $\mathrm{X}_{\mathrm{L}}$ [148].

Finally, Cur exerts an indirect proapoptotic activity by damaging mtDNA. Indeed, the prooxidant activity of Cur at high concentrations damages both mtDNA and nDNA in HepG2 cells, but with a more dramatic effect on mtDNA [135, 136]. Such damage causes impairment of OXPHOS, reduces ATP synthesis, and renders cells more prone to cell death. The observation that mtDNA-depleted cells are resistant to Cur-induced apoptosis further confirms the essential role of mtDNA in the sensitivity to cell death [137].

\section{Concluding Remarks}

Natural compounds display a panoply of effects on mitochondria, affecting virtually every function correlated with the biology of the organelle. Data concerning differential effects on cancerous and normal, nontransformed cells are particularly interesting for possible, therapeutic use of these molecules as chemotherapeutics or chemopreventers. Furthermore, as aging in mammals is associated with mitochondrial oxidative stress in virtually every tissue [149153], the use of these molecules, and particularly RSV, as antiaging agents is considered of particular interest [154157]. Nevertheless, several problems must be solved before thinking of a wide, systematic use of these natural compounds in the clinical practice.

First, contradictory data have been obtained in different cell models, and these discrepancies need urgent clarification, particularly to understand which are the doses that display beneficiary on mitochondria, without causing collateral, dangerous effects. Second, rigorous studies on large cohorts of subjects are urgently needed to clearly define the daily intake and bioavailability of these natural compounds. Indeed, the actual clinical potential of these molecules cannot be fully established until proper protocols providing optimal 
bioavailability to ensure sufficient tissue distribution are established. Third, studies on natural compounds of vegetal origin are usually focused on few, well-known molecules or on herbal extracts whose composition is barely known and often nonstandardized. The expansion of the array of molecules analysed in depth as Qu, RSV, or Cur will open new perspectives in the modulation of mitochondrial functions related with the onset of human diseases.

\section{Disclosure}

Andrea Cossarizza and Marcello Pinti coshare senior authorship.

\section{Conflict of Interests}

The authors declare no conflict of interests.

\section{Acknowledgments}

This study has been supported by Fondazione di Vignola (grant to Marcello Pinti) and by Ministero dell'Istruzione, dell'Università e della Ricerca (MIUR) (Grant no. RBAP11S8C3 to Andrea Cossarizza).

\section{References}

[1] M. R. Duchen, "Mitochondria in health and disease: perspectives on a new mitochondrial biology," Molecular Aspects of Medicine, vol. 25, no. 4, pp. 365-451, 2004.

[2] L. Galluzzi, O. Kepp, and G. Kroemer, "Mitochondria: master regulators of danger signalling," Nature Reviews Molecular Cell Biology, vol. 13, no. 12, pp. 780-788, 2012.

[3] L. Galluzzi, O. Kepp, C. Trojel-Hansen, and G. Kroemer, "Mitochondrial control of cellular life, stress, and death," Circulation Research, vol. 111, no. 9, pp. 1198-1207, 2012.

[4] L. Galluzzi, E. Morselli, O. Kepp, I. Vitale, M. Pinti, and G. Kroemer, "Mitochondrial liaisons of p53," Antioxidants \& Redox Signaling, vol. 15, no. 6, pp. 1691-1714, 2011.

[5] M. Rigoulet, E. D. Yoboue, and A. Devin, "Mitochondrial ROS generation and its regulation: mechanisms involved in $\mathrm{H}_{2} \mathrm{O}_{2}$ signaling," Antioxidants \& Redox Signaling, vol. 14, no. 3, pp. 459-468, 2011.

[6] D. C. Wallace, "A mitochondrial paradigm of metabolic and degenerative diseases, aging, and cancer: a dawn for evolutionary medicine," Annual Review of Genetics, vol. 39, pp. 359-407, 2005.

[7] M. Pinti, C. Mussini, and A. Cossarizza, "Mitochondrial DNA: a proinflammatory 'enemy from within' during HIV infection?" Cell Death and Disease, vol. 3, no. 5, article e307, 2012.

[8] G. Sgarbi, P. Matarrese, M. Pinti et al., "Mitochondria hyperfusion and elevated autophagic activity are key mechanisms for cellular bioenergetic preservation in centenarians," Aging, vol. 6, no. 4, pp. 296-310, 2014.

[9] D. Monti, S. Salvioli, M. Capri et al., "Decreased susceptibility to oxidative stress-induced apoptosis of peripheral blood mononuclear cells from healthy elderly and centenarians," Mechanisms of Ageing and Development, vol. 121, no. 1-3, pp. 239-250, 2001.
[10] R. Ferraresi, L. Troiano, M. Pinti et al., "Resistance of mtDNAdepleted cells to apoptosis," Cytometry A, vol. 73, no. 6, pp. 528537, 2008.

[11] L. Gibellini, M. Pinti, M. Nasi et al., "Interfering with ROS metabolism in cancer cells: the potential role of quercetin," Cancers, vol. 2, no. 2, pp. 1288-1311, 2010.

[12] C. Giordano, M. Sebastiani, G. Plazzi et al., "Mitochondrial neurogastrointestinal encephalomyopathy: evidence of mitochondrial DNA depletion in the small intestine," Gastroenterology, vol. 130, no. 3, pp. 893-901, 2006.

[13] G. Kroemer, L. Galluzzi, and C. Brenner, "Mitochondrial membrane permeabilization in cell death," Physiological Reviews, vol. 87, no. 1, pp. 99-163, 2007.

[14] S. Fulda, L. Galluzzi, and G. Kroemer, "Targeting mitochondria for cancer therapy," Nature Reviews Drug Discovery, vol. 9, no. 6, pp. 447-464, 2010.

[15] A. Cossarizza, G. Kalashnikova, E. Grassilli et al., "Mitochondrial modifications during rat thymocyte apoptosis: a study at the single cell level," Experimental Cell Research, vol. 214, no. 1, pp. 323-330, 1994.

[16] M. Garcia Fernandez, L. Troiano, L. Moretti et al., "Early changes in intramitochondrial cardiolipin distribution during apoptosis," Cell Growth and Differentiation, vol. 13, no. 9, pp. 449455, 2002.

[17] D. Monti, E. Grassilli, L. Troiano et al., "Senescence, immortalization, and apoptosis: an intriguing relationship," Annals of the New York Academy of Sciences, vol. 673, pp. 70-82, 1992.

[18] M. Pinti, P. Salomoni, and A. Cossarizza, "Anti-HIV drugs and the mitochondria," Biochimica et Biophysica Acta: Bioenergetics, vol. 1757, no. 5-6, pp. 700-707, 2006.

[19] J. R. Gledhill, M. G. Montgomery, A. G. W. Leslie, and J. E. Walker, "Mechanism of inhibition of bovine F1-ATPase by resveratrol and related polyphenols," Proceedings of the National Academy of Sciences of the United States of America, vol. 104, no. 34, pp. 13632-13637, 2007.

[20] J. R. Gledhill and J. E. Walker, "Inhibition sites in $\mathrm{F}_{1}$-ATPase from bovine heart mitochondria," Biochemical Journal, vol. 386, part 3, pp. 591-598, 2005.

[21] J. L. Kipp and V. D. Ramirez, "Effect of estradiol, diethylstilbestrol, and resveratrol on F0F1-ATPase activity from mitochondrial preparations of rat heart, liver, and brain," Endocrine, vol. 15, no. 2, pp. 165-175, 2001.

[22] M. Sekiya, R. Hisasaka, A. Iwamoto-Kihara, M. Futai, and M. Nakanishi-Matsui, "A unique mechanism of curcumin inhibition on F1 ATPase," Biochemical and Biophysical Research Communications, vol. 452, no. 4, pp. 940-944, 2014.

[23] J. Zheng and V. D. Ramirez, "Inhibition of mitochondrial proton F0F1-ATPase/ATP synthase by polyphenolic phytochemicals," British Journal of Pharmacology, vol. 130, no. 5, pp. 1115-1123, 2000.

[24] P. C. H. Hollman and M. B. Katan, "Dietary flavonoids: Intake, health effects and bioavailability," Food and Chemical Toxicology, vol. 37, no. 9-10, pp. 937-942, 1999.

[25] L. Gibellini, M. Pinti, M. Nasi et al., "Quercetin and cancer chemoprevention," Evidence-Based Complementary and Alternative Medicine, vol. 2011, Article ID 591356, 15 pages, 2011.

[26] B. B. Aggarwal, A. Kumar, and A. C. Bharti, "Anticancer potential of curcumin: preclinical and clinical studies," Anticancer Research, vol. 23, no. 1, pp. 363-398, 2003. 
[27] V. Basile, E. Ferrari, S. Lazzari, S. Belluti, F. Pignedoli, and C. Imbriano, "Curcumin derivatives: molecular basis of their anticancer activity," Biochemical Pharmacology, vol. 78, no. 10, pp. 1305-1315, 2009.

[28] R. P. Sahu, S. Batra, and S. K. Srivastava, "Activation of ATM/ Chk1 by curcumin causes cell cycle arrest and apoptosis in human pancreatic cancer cells," British Journal of Cancer, vol. 100, no. 9, pp. 1425-1433, 2009.

[29] S.-H. Jee, S.-C. Shen, C.-R. Tseng, H.-C. Chiu, and M.-L. Kuo, "Curcumin induces a p53-dependent apoptosis in human basal cell carcinoma cells," Journal of Investigative Dermatology, vol. 111, no. 4, pp. 656-661, 1998.

[30] T. Kawamori, R. Lubet, V. E. Steele et al., "Chemopreventive effect of curcumin, a naturally occurring anti-inflammatory agent, during the promotion/progression stages of colon cancer," Cancer Research, vol. 59, no. 3, pp. 597-601, 1999.

[31] K. Mehta, P. Pantazis, T. McQueen, and B. B. Aggarwal, "Antiproliferative effect of curcumin (diferuloylmethane) against human breast tumor cell lines," Anti-Cancer Drugs, vol. 8, no. 5, pp. 470-481, 1997.

[32] R. Hayun, E. Okun, A. Berrebi et al., "Rapamycin and curcumin induce apoptosis in primary resting B chronic lymphocytic leukemia cells," Leukemia and Lymphoma, vol. 50, no. 4, pp. 625-632, 2009.

[33] S. Purkayastha, A. Berliner, S. S. Fernando et al., "Curcumin blocks brain tumor formation," Brain Research, vol. 1266, pp. 130-138, 2009.

[34] M. Sekiya, E. Chiba, M. Satoh et al., "Strong inhibitory effects of curcumin and its demethoxy analog on Escherichia coli ATP synthase F1 sector," International Journal of Biological Macromolecules, vol. 70, pp. 241-245, 2014.

[35] M. Sekiya, R. K. Nakamoto, M. Nakanishi-Matsui, and M. Futai, "Binding of phytopolyphenol piceatannol disrupts $\beta / \gamma$ subunit interactions and rate-limiting step of steady-state rotational catalysis in Escherichia coli $\mathrm{F}_{1}$-ATpase," The Journal of Biological Chemistry, vol. 287, no. 27, pp. 22771-22780, 2012.

[36] M. Fiorani, A. Guidarelli, M. Blasa et al., "Mitochondria accumulate large amounts of quercetin: prevention of mitochondrial damage and release upon oxidation of the extramitochondrial fraction of the flavonoid," Journal of Nutritional Biochemistry, vol. 21, no. 5, pp. 397-404, 2010.

[37] D. R. Lang and E. Racker, "Effects of quercetin and F1 inhibitor on mitochondrial ATPase and energy-linked reactions in submitochondrial particles," Biochimica et Biophysica Acta, vol. 333, no. 2, pp. 180-186, 1974.

[38] R. Ortega and N. García, "The flavonoid quercetin induces changes in mitochondrial permeability by inhibiting adenine nucleotide translocase," Journal of Bioenergetics and Biomembranes, vol. 41, no. 1, pp. 41-47, 2009.

[39] D. J. Dorta, A. A. Pigoso, F. E. Mingatto et al., "The interaction of flavonoids with mitochondria: effects on energetic processes," Chemico-Biological Interactions, vol. 152, no. 2-3, pp. 67-78, 2005.

[40] S. Trumbeckaite, J. Bernatoniene, D. Majiene, V. Jakštas, A. Savickas, and A. Toleikis, "The effect of flavonoids on rat heart mitochondrial function," Biomedicine and Pharmacotherapy, vol. 60, no. 5, pp. 245-248, 2006.

[41] M. Lagouge, C. Argmann, Z. Gerhart-Hines et al., "Resveratrol improves mitochondrial function and protects against metabolic disease by activating SIRT1 and PGC-1 $\alpha$," Cell, vol. 127, no. 6, pp. 1109-1122, 2006.
[42] T. Murase, S. Haramizu, N. Ota, and T. Hase, "Suppression of the aging-associated decline in physical performance by a combination of resveratrol intake and habitual exercise in senescence-accelerated mice," Biogerontology, vol. 10, no. 4, pp. 423-434, 2009.

[43] N. Hart, L. Sarga, Z. Csende et al., "Resveratrol attenuates exercise-induced adaptive responses in rats selectively bred for low running performance," Dose-Response, vol. 12, no. 1, pp. 57-71, 2014.

[44] N. Hart, L. Sarga, Z. Csende et al., "Resveratrol enhances exercise training responses in rats selectively bred for high running performance," Food and Chemical Toxicology, vol. 61, pp. 53-59, 2013.

[45] H. W. Lim, H. Y. Lim, and K. P. Wong, "Uncoupling of oxidative phosphorylation by curcumin: implication of its cellular mechanism of action," Biochemical and Biophysical Research Communications, vol. 389, no. 1, pp. 187-192, 2009.

[46] B. Chance and G. Hollunger, "The interaction of energy and electron transfer reactions in mitochondria. I. General properties and nature of the products of succinate-linked reduction of pyridine nucleotide," The Journal of Biological Chemistry, vol. 236, pp. 1534-1543, 1961.

[47] E. B. Tahara, F. D. T. Navarete, and A. J. Kowaltowski, “Tissue-, substrate-, and site-specific characteristics of mitochondrial reactive oxygen species generation," Free Radical Biology and Medicine, vol. 46, no. 9, pp. 1283-1297, 2009.

[48] C. G. M. Heijnen, G. R. M. M. Haenen, F. A. A. van Acker, W. J. F. van der Vijgh, and A. Bast, "Flavonoids as peroxynitrite scavengers: the role of the hydroxyl groups," Toxicology in Vitro, vol. 15, no. 1, pp. 3-6, 2001.

[49] D. Metodiewa, A. K. Jaiswal, N. Cenas, E. Dickancaité, and J. Segura-Aguilar, "Quercetin may act as a cytotoxic prooxidant after its metabolic activation to semiquinone and quinoidal product," Free Radical Biology and Medicine, vol. 26, no. 1-2, pp. 107-116, 1999.

[50] M. Yoshino, M. Haneda, M. Naruse, and K. Murakami, "Prooxidant activity of flavonoids: copper-dependent strand breaks and the formation of 8-hydroxy-2' -deoxyguanosine in DNA," Molecular Genetics and Metabolism, vol. 68, no. 4, pp. 468-472, 1999.

[51] A. M. Ramos and P. Aller, "Quercetin decreases intracellular GSH content and potentiates the apoptotic action of the antileukemic drug arsenic trioxide in human leukemia cell lines," Biochemical Pharmacology, vol. 75, no. 10, pp. 1912-1923, 2008.

[52] R. Ferraresi, L. Troiano, E. Roat et al., "Essential requirement of reduced glutathione (GSH) for the anti-oxidant effect of the flavonoid quercetin," Free Radical Research, vol. 39, no. 11, pp. 1249-1258, 2005.

[53] R. Kachadourian and B. J. Day, "Flavonoid-induced glutathione depletion: potential implications for cancer treatment," Free Radical Biology and Medicine, vol. 41, no. 1, pp. 65-76, 2006.

[54] A. W. Boots, N. Kubben, G. R. M. M. Haenen, and A. Bast, "Oxidized quercetin reacts with thiols rather than with ascorbate: implication for quercetin supplementation," Biochemical and Biophysical Research Communications, vol. 308, no. 3, pp. 560-565, 2003.

[55] S. C. Sahu and G. C. Gray, "Pro-oxidant activity of flavanoids: effects on glutathione and glutathione S-transferase in isolated rat liver nuclei," Cancer Letters, vol. 104, no. 2, pp. 193 196, 1996. 
[56] J. Lu, L. V. Papp, J. Fang, S. Rodriguez-Nieto, B. Zhivotovsky, and A. Holmgren, "Inhibition of mammalian thioredoxin reductase by some flavonoids: implications for myricetin and quercetin anticancer activity," Cancer Research, vol. 66, no. 8, pp. 44104418, 2006.

[57] J. D. Hayes and A. T. Dinkova-Kostova, "The Nrf2 regulatory network provides an interface between redox and intermediary metabolism," Trends in Biochemical Sciences, vol. 39, no. 4, pp. 199-218, 2014.

[58] K. Itoh, P. Ye, T. Matsumiya, K. Tanji, and T. Ozaki, "Emerging functional cross-talk between the Keap1-Nrf2 system and mitochondria," Journal of Clinical Biochemistry and Nutrition, vol. 56, no. 2, pp. 91-97, 2015.

[59] A. B. Granado-Serrano, M. A. Martín, L. Bravo, L. Goya, and S. Ramos, "Quercetin modulates Nrf2 and glutathionerelated defenses in HepG2 cells: involvement of p38," ChemicoBiological Interactions, vol. 195, no. 2, pp. 154-164, 2012.

[60] S. Tanigawa, M. Fujii, and D.-X. Hou, "Action of Nrf2 and Keap1 in ARE-mediated NQO1 expression by quercetin," Free Radical Biology and Medicine, vol. 42, no. 11, pp. 1690-1703, 2007.

[61] J. Sanhueza, J. Valdes, R. Campos, A. Garrido, and A. Valenzuela, "Changes in the xanthine dehydrogenase/xanthine oxidase ratio in the rat kidney subjected to ischemia-reperfusion stress: preventive effect of some flavonoids," Research Communications in Chemical Pathology and Pharmacology, vol. 78, no. 2, pp. 211-218, 1992.

[62] O. Çevik, S. Çadrc, T. E. Şener et al., "Quercetin treatment against ischemia/reperfusion injury in rat corpus cavernosum tissue: a role on apoptosis and oxidative stress," Free Radical Research, vol. 47, no. 9, pp. 683-691, 2013.

[63] A. Ghosh, S. Sarkar, A. K. Mandal, and N. Das, "Neuroprotective role of nanoencapsulated quercetin in combating ischemiareperfusion induced neuronal damage in young and aged rats," PLoS ONE, vol. 8, no. 4, Article ID e57735, 2013.

[64] P. Lorenz, S. Roychowdhury, M. Engelmann, G. Wolf, and T. F. W. Horn, "Oxyresveratrol and resveratrol are potent antioxidants and free radical scavengers: effect on nitrosative and oxidative stress derived from microglial cells," Nitric Oxide: Biology and Chemistry, vol. 9, no. 2, pp. 64-76, 2003.

[65] P. Guha, A. Dey, M. V. Dhyani et al., "Calpain and caspase orchestrated death signal to accomplish apoptosis induced by resveratrol and its novel analog hydroxstilbene-1 in cancer cells," Journal of Pharmacology and Experimental Therapeutics, vol. 334, no. 2, pp. 381-394, 2010.

[66] S. S. Leonard, C. Xia, B.-H. Jiang et al., "Resveratrol scavenges reactive oxygen species and effects radical-induced cellular responses," Biochemical and Biophysical Research Communications, vol. 309, no. 4, pp. 1017-1026, 2003.

[67] L.-M. Hung, M.-J. Su, W.-K. Chu, C.-W. Chiao, W.-F. Chan, and J.-K. Chen, "The protective effect of resveratrols on ischaemiareperfusion injuries of rat hearts is correlated with antioxidant efficacy," British Journal of Pharmacology, vol. 135, no. 7, pp. 1627-1633, 2002.

[68] Y.-G. Li, W. Zhu, J.-P. Tao et al., "Resveratrol protects cardiomyocytes from oxidative stress through SIRT1 and mitochondrial biogenesis signaling pathways," Biochemical and Biophysical Research Communications, vol. 438, no. 2, pp. 270-276, 2013.

[69] M. Shen, R.-X. Wu, L. Zhao et al., "Resveratrol attenuates ischemia/reperfusion injury in neonatal cardiomyocytes and its underlying mechanism," PLoS ONE, vol. 7, no. 12, Article ID e51223, 2012.
[70] H. Zheng, H. Guo, Y. Hong, F. Zheng, and J. Wang, “The effects of age and resveratrol on the hypoxic preconditioning protection against hypoxia-reperfusion injury: studies in rat hearts and human cardiomyocytes," European Journal of CardioThoracic Surgery, 2015.

[71] E. Hirzel, P. W. Lindinger, S. Maseneni et al., "Differential modulation of ROS signals and other mitochondrial parameters by the antioxidants MitoQ, resveratrol and curcumin in human adipocytes," Journal of Receptors and Signal Transduction, vol. 33, no. 5, pp. 304-312, 2013.

[72] B. Bellaver, D. G. Souza, D. O. Souza, and A. Quincozes-Santos, "Resveratrol increases antioxidant defenses and decreases proinflammatory cytokines in hippocampal astrocyte cultures from newborn, adult and aged Wistar rats," Toxicology in Vitro, vol. 28, no. 4, pp. 479-484, 2014.

[73] J. Soeur, J. Eilstein, G. Léreaux, C. Jones, and L. Marrot, "Skin resistance to oxidative stress induced by resveratrol: from Nrf2 activation to GSH biosynthesis," Free Radical Biology and Medicine, vol. 78, pp. 213-223, 2015.

[74] X. Zhou, M. Chen, X. Zeng et al., "Resveratrol regulates mitochondrial reactive oxygen species homeostasis through Sirt3 signaling pathway in human vascular endothelial cells," Cell Death and Disease, vol. 5, no. 12, Article ID e1576, 2014.

[75] Z. Ungvari, Z. Bagi, A. Feher et al., "Resveratrol confers endothelial protection via activation of the antioxidant transcription factor Nrf2," American Journal of Physiology-Heart and Circulatory Physiology, vol. 299, no. 1, pp. H18-H24, 2010.

[76] Z. Ungvari, Z. Orosz, A. Rivera et al., "Resveratrol increases vascular oxidative stress resistance," The American Journal of Physiology-Heart and Circulatory Physiology, vol. 292, no. 5, pp. H2417-H2424, 2007.

[77] Z. Ungvari, N. Labinskyy, P. Mukhopadhyay et al., "Resveratrol attenuates mitochondrial oxidative stress in coronary arterial endothelial cells," The American Journal of Physiology-Heart and Circulatory Physiology, vol. 297, no. 5, pp. H1876-H1881, 2009.

[78] W.-H. Chan, H.-J. Wu, and Y.-D. Hsuuw, "Curcumin inhibits ROS formation and apoptosis in methylglyoxal-treated human hepatoma G2 cells," Annals of the New York Academy of Sciences, vol. 1042, pp. 372-378, 2005.

[79] J. M. Woo, D.-Y. Shin, S. J. Lee et al., "Curcumin protects retinal pigment epithelial cells against oxidative stress via induction of heme oxygenase-1 expression and reduction of reactive oxygen," Molecular Vision, vol. 18, pp. 901-908, 2012.

[80] H. Jiang, X. Tian, Y. Guo, W. Duan, H. Bu, and C. Li, "Activation of nuclear factor erythroid 2-related factor 2 cytoprotective signaling by curcumin protect primary spinal cord astrocytes against oxidative toxicity," Biological and Pharmaceutical Bulletin, vol. 34, no. 8, pp. 1194-1197, 2011.

[81] P. Manikandan, M. Sumitra, S. Aishwarya, B. M. Manohar, B. Lokanadam, and R. Puvanakrishnan, "Curcumin modulates free radical quenching in myocardial ischaemia in rats," The International Journal of Biochemistry \& Cell Biology, vol. 36, no. 10, pp. 1967-1980, 2004.

[82] T. Ak and I. Gülçin, "Antioxidant and radical scavenging properties of curcumin," Chemico-Biological Interactions, vol. 174, no. 1, pp. 27-37, 2008.

[83] S. Derochette, T. Franck, A. Mouithys-Mickalad et al., "Curcumin and resveratrol act by different ways on NADPH oxidase activity and reactive oxygen species produced by equine neutrophils," Chemico-Biological Interactions, vol. 206, no. 2, pp. 186-193, 2013. 
[84] A. Barzegar and A. A. Moosavi-Movahedi, "Intracellular ROS protection efficiency and free radical-scavenging activity of curcumin," PLoS ONE, vol. 6, no. 10, Article ID e26012, 2011.

[85] J. E. Kim, A. R. Kim, H. Y. Chung, S. Y. Han, B. S. Kim, and J. S. Choi, "In vitro peroxynitrite scavenging activity of diarylheptanoids from Curcuma longa," Phytotherapy Research, vol. 17, no. 5, pp. 481-484, 2003.

[86] Y. Sumanont, Y. Murakami, M. Tohda, O. Vajragupta, K. Matsumoto, and H. Watanabe, "Evaluation of the nitric oxide radical scavenging activity of manganese complexes of curcumin and its derivative," Biological and Pharmaceutical Bulletin, vol. 27, no. 2, pp. 170-173, 2004.

[87] H. D. Panchal, K. Vranizan, C. Y. Lee, J. Ho, J. Ngai, and P. S. Timiras, "Early anti-oxidative and anti-proliferative curcumin effects on neuroglioma cells suggest therapeutic targets," Neurochemical Research, vol. 33, no. 9, pp. 1701-1710, 2008.

[88] G. S. Jeong, G. S. Oh, H. O. Pae et al., "Comparative effects of curcuminoids on endothelial heme oxygenase-1 expression: ortho-methoxy groups are essential to enhance heme oxygenase activity and protection," Experimental \& Molecular Medicine, vol. 38, no. 4, pp. 393-400, 2006.

[89] L. M. Reyes-Fermín, S. González-Reyes, N. G. Tarco-Álvarez, M. Hernández-Nava, M. Orozco-Ibarra, and J. PedrazaChaverri, "Neuroprotective effect of $\alpha$-mangostin and curcumin against iodoacetate-induced cell death," Nutritional Neuroscience, vol. 15, no. 5, pp. 34-41, 2012.

[90] L. P. Yarru, R. S. Settivari, N. K. S. Gowda, E. Antoniou, D. R. Ledoux, and G. E. Rottinghaus, "Effects of turmeric (Curcuma longa) on the expression of hepatic genes associated with biotransformation, antioxidant, and immune systems in broiler chicks fed aflatoxin," Poultry Science, vol. 88, no. 12, pp. 2620-2627, 2009.

[91] E. Balogun, R. Foresti, C. J. Green, and R. Motterlini, “Changes in temperature modulate heme oxygenase-1 induction by curcumin in renal epithelial cells," Biochemical and Biophysical Research Communications, vol. 308, no. 4, pp. 950-955, 2003.

[92] E. Balogun, M. Hoque, P. Gong et al., "Curcumin activates the haem oxygenase-1 gene via regulation of $\mathrm{Nrf} 2$ and the antioxidant-responsive element," Biochemical Journal, vol. 371, no. 3, pp. 887-895, 2003.

[93] S. Gao, X. Duan, X. Wang et al., "Curcumin attenuates arsenicinduced hepatic injuries and oxidative stress in experimental mice through activation of Nrf2 pathway, promotion of arsenic methylation and urinary excretion," Food and Chemical Toxicology, vol. 59, pp. 739-747, 2013.

[94] R. Garg, S. Gupta, and G. B. Maru, "Dietary curcumin modulates transcriptional regulators of phase I and phase II enzymes in benzo $[\alpha]$ pyrene-treated mice: mechanism of its antiinitiating action," Carcinogenesis, vol. 29, no. 5, pp. 1022-1032, 2008.

[95] A. González-Salazar, E. Molina-Jijón, F. Correa et al., "Curcumin protects from cardiac reperfusion damage by attenuation of oxidant stress and mitochondrial dysfunction," Cardiovascular Toxicology, vol. 11, no. 4, pp. 357-364, 2011.

[96] F. Correa, M. Buelna-Chontal, S. Hernández-Reséndiz et al., "Curcumin maintains cardiac and mitochondrial function in chronic kidney disease," Free Radical Biology and Medicine, vol. 61, pp. 119-129, 2013.

[97] E. Molina-Jijón, E. Tapia, C. Zazueta et al., "Curcumin prevents $\mathrm{Cr}(\mathrm{VI})$-induced renal oxidant damage by a mitochondrial pathway," Free Radical Biology and Medicine, vol. 51, no. 8, pp. 15431557, 2011.
[98] A. K. Chandra, A. Chatterjee, R. Ghosh, and M. Sarkar, "Effect of curcumin on chromium-induced oxidative damage in male reproductive system," Environmental Toxicology and Pharmacology, vol. 24, no. 2, pp. 160-166, 2007.

[99] W. R. García-Niño, E. Tapia, C. Zazueta et al., "Curcumin pretreatment prevents potassium dichromate-induced hepatotoxicity, oxidative stress, decreased respiratory complex I activity, and membrane permeability transition pore opening," Evidence-Based Complementary and Alternative Medicine, vol. 2013, Article ID 424692, 19 pages, 2013.

[100] N. Sivalingam, J. Basivireddy, K. A. Balasubramanian, and M. Jacob, "Curcumin attenuates indomethacin-induced oxidative stress and mitochondrial dysfunction," Archives of Toxicology, vol. 82, no. 7, pp. 471-481, 2008.

[101] S. Fulda, "Modulation of apoptosis by natural products for cancer therapy," Planta Medica, vol. 76, no. 11, pp. 1075-1079, 2010.

[102] N. Rayamajhi, S.-K. Kim, H. Go et al., "Quercetin induces mitochondrial biogenesis through activation of HO-1 in HepG2 cells," Oxidative Medicine and Cellular Longevity, vol. 2013, Article ID 154279, 10 pages, 2013.

[103] D. C. Nieman, A. S. Williams, R. A. Shanely et al., "Quercetin's influence on exercise performance and muscle mitochondrial biogenesis," Medicine and Science in Sports and Exercise, vol. 42, no. 2, pp. 338-345, 2010.

[104] S. M. Kwon, H. G. Park, J. K. Jun, and W. L. Lee, "Exercise, but not quercetin, ameliorates inflammation, mitochondrial biogenesis, and lipid metabolism in skeletal muscle after strenuous exercise by high-fat diet mice," The Journal of Exercise Nutrition and Biochemistry, vol. 6, no. 1, pp. 51-60, 1975.

[105] R. A. Casuso, E. J. Martínez-López, F. Hita-Contreras et al., "The combination of oral quercetin supplementation and exercise prevents brain mitochondrial biogenesis," Genes \& Nutrition, vol. 9, no. 5, p. 420, 2014.

[106] T.-J. Lee, O. H. Kim, Y. H. Kim et al., "Quercetin arrests G2/M phase and induces caspase-dependent cell death in U937 cells," Cancer Letters, vol. 240, no. 2, pp. 234-242, 2006.

[107] J.-H. Yang, T.-C. Hsia, H.-M. Kuo et al., "Inhibition of lung cancer cell growth by quercetin glucuronides via $\mathrm{G}_{2} / \mathrm{M}$ arrest and induction of apoptosis," Drug Metabolism and Disposition, vol. 34, no. 2, pp. 296-304, 2006.

[108] S.-Y. Chien, Y.-C. Wu, J.-G. Chung et al., "Quercetin-induced apoptosis acts through mitochondrial- and caspase-3-dependent pathways in human breast cancer MDA-MB-231 cells," Human and Experimental Toxicology, vol. 28, no. 8, pp. 493-503, 2009.

[109] A. B. Granado-Serrano, M. A. Martín, L. Bravo, L. Goya, and S. Ramos, "Quercetin induces apoptosis via caspase activation, regulation of Bcl-2, and inhibition of PI-3-kinase/Akt and ERK pathways in a human hepatoma cell line (HepG2)," Journal of Nutrition, vol. 136, no. 11, pp. 2715-2721, 2006.

[110] J. Tan, B. Wang, and L. Zhu, "Regulation of survivin and Bcl-2 in HepG2 cell apoptosis induced by quercetin," Chemistry and Biodiversity, vol. 6, no. 7, pp. 1101-1110, 2009.

[111] L. Troiano, R. Ferraresi, E. Lugli et al., "Multiparametric analysis of cells with different mitochondrial membrane potential during apoptosis by polychromatic flow cytometry," Nature Protocols, vol. 2, no. 11, pp. 2719-2727, 2007.

[112] E. Lugli, R. Ferraresi, E. Roat et al., "Quercetin inhibits lymphocyte activation and proliferation without inducing apoptosis in peripheral mononuclear cells," Leukemia Research, vol. 33, no. 1, pp. 140-150, 2009. 
[113] J.-H. Jeong, J. Y. An, Y. T. Kwon, J. G. Rhee, and Y. J. Lee, “Effects of low dose quercetin: cancer cell-specific inhibition of cell cycle progression," Journal of Cellular Biochemistry, vol. 106, no. 1, pp. 73-82, 2009.

[114] Y.-K. Lee, J.-T. Hwang, D. Y. Kwon, Y.-J. Surh, and O. J. Park, "Induction of apoptosis by quercetin is mediated through AMPK $\alpha 1 /$ ASK1/p38 pathway," Cancer Letters, vol. 292, no. 2, pp. 228-236, 2010.

[115] A. Matsuzawa and H. Ichijo, "Redox control of cell fate by MAP kinase: physiological roles of ASK1-MAP kinase pathway in stress signaling," Biochimica et Biophysica Acta-General Subjects, vol. 1780, no. 11, pp. 1325-1336, 2008.

[116] Y.-K. Lee, Y. P. Song, Y.-M. Kim, S. L. Won, and J. P. Ock, "AMP kinase/cyclooxygenase-2 pathway regulates proliferation and apoptosis of cancer cells treated with quercetin," Experimental and Molecular Medicine, vol. 41, no. 3, pp. 201-207, 2009.

[117] G. T. Kim, S. H. Lee, and Y. M. Kim, "Quercetin regulates sestrin 2-AMPK-mTOR signaling pathway and induces apoptosis via increased intracellular ROS in HCT116 colon cancer cells," Journal of Cancer Prevention, vol. 18, no. 3, pp. 264-270, 2013.

[118] J.-H. Um, S.-J. Park, H. Kang et al., "AMP-activated protein kinase-deficient mice are resistant to the metabolic effects of resveratrol," Diabetes, vol. 59, no. 3, pp. 554-563, 2010.

[119] K. J. Menzies, K. Singh, A. Saleem, and D. A. Hood, "Sirtuin 1-mediated effects of exercise and resveratrol on mitochondrial biogenesis," The Journal of Biological Chemistry, vol. 288, no. 10, pp. 6968-6979, 2013.

[120] S. Chung, H. Yao, S. Caito, J.-W. Hwang, G. Arunachalam, and I. Rahman, "Regulation of SIRT1 in cellular functions: role of polyphenols," Archives of Biochemistry and Biophysics, vol. 501, no. 1, pp. 79-90, 2010.

[121] K. T. Howitz, K. J. Bitterman, H. Y. Cohen et al., "Small molecule activators of sirtuins extend Saccharomyces cerevisiae lifespan," Nature, vol. 425, no. 6954, pp. 191-196, 2003.

[122] M. Pacholec, J. E. Bleasdale, B. Chrunyk et al., "SRT1720, SRT2183, SRT1460, and resveratrol are not direct activators of SIRT1," Journal of Biological Chemistry, vol. 285, no. 11, pp. 83408351, 2010.

[123] D. Beher, J. Wu, S. Cumine et al., "Resveratrol is not a direct activator of SIRT1 enzyme activity," Chemical Biology and Drug Design, vol. 74, no. 6, pp. 619-624, 2009.

[124] K. Higashida, S. H. Kim, S. R. Jung, M. Asaka, J. O. Holloszy, and D.-H. Han, "Effects of resveratrol and SIRT1 on PGC- $1 \alpha$ activity and mitochondrial biogenesis: a reevaluation," PLoS Biology, vol. 11, no. 7, Article ID e1001603, 2013.

[125] D. Sareen, S. R. Darjatmoko, D. M. Albert, and A. S. Polans, "Mitochondria, calcium, and calpain are key mediators of resveratrol-induced apoptosis in breast cancer," Molecular Pharmacology, vol. 72, no. 6, pp. 1466-1475, 2007.

[126] X. Ma, X. Tian, X. Huang, F. Yan, and D. Qiao, "Resveratrolinduced mitochondrial dysfunction and apoptosis are associated with $\mathrm{Ca}^{2+}$ and mCICR-mediated MPT activation in HepG2 cells," Molecular and Cellular Biochemistry, vol. 302, no. 1-2, pp. 99-109, 2007.

[127] S. Fulda and K.-M. Debatin, "Sensitization for tumor necrosis factor-related apoptosis-inducing ligand-induced apoptosis by the chemopreventive agent resveratrol," Cancer Research, vol. 64, no. 1, pp. 337-346, 2004.
[128] A. R. Jazirehi and B. Bonavida, "Resveratrol modifies the expression of apoptotic regulatory proteins and sensitizes nonHodgkin's lymphoma and multiple myeloma cell lines to paclitaxel-induced apoptosis," Molecular Cancer Therapeutics, vol. 3, no. 1, pp. 71-84, 2004.

[129] A. Bhardwaj, G. Sethi, S. Vadhan-Raj et al., "Resveratrol inhibits proliferation, induces apoptosis, and overcomes chemoresistance through down-regulation of STAT3 and nuclear factorkappaB-regulated antiapoptotic and cell survival gene products in human multiple myeloma cells," Blood, vol. 109, no. 6, pp. 2293-2302, 2007.

[130] J.-W. Park, Y.-J. Choi, S.-I. Suh et al., "Bcl-2 overexpression attenuates resveratrol-induced apoptosis in U937 cells by inhibition of caspase-3 activity," Carcinogenesis, vol. 22, no. 10, pp. $1633-1639,2001$.

[131] L. Tessitore, A. Davit, I. Sarotto, and G. Caderni, "Resveratrol depresses the growth of colorectal aberrant crypt foci by affecting bax and p21(CIP) expression," Carcinogenesis, vol. 21, no. 8, pp. 1619-1622, 2000.

[132] M. Mahyar-Roemer, A. Katsen, P. Mestres, and K. Roemer, "Resveratrol induces colon tumor cell apoptosis independently of p53 and precede by epithelial differentiation, mitochondrial proliferation and membrane potential collapse," International Journal of Cancer, vol. 94, no. 5, pp. 615-622, 2001.

[133] M. Mahyar-Roemer, H. Köhler, and K. Roemer, "Role of Bax in resveratrol-induced apoptosis of colorectal carcinoma cells," BMC Cancer, vol. 2, no. 1, article 27, 2002.

[134] J.-J. Kuo, H.-H. Chang, T.-H. Tsai, and T.-Y. Lee, "Curcumin ameliorates mitochondrial dysfunction associated with inhibition of gluconeogenesis in free fatty acid-mediated hepatic lipoapoptosis," International Journal of Molecular Medicine, vol. 30, no. 3, pp. 643-649, 2012.

[135] J. Cao, L. Jia, H.-M. Zhou, Y. Liu, and L.-F. Zhong, "Mitochondrial and nuclear DNA damage induced by curcumin in human hepatoma G2 cells," Toxicological Sciences, vol. 91, no. 2, pp. 476483, 2006.

[136] Y. Kim, H. D. Kim, and J. Kim, "Cytoplasmic ribosomal protein S3 (rpS3) plays a pivotal role in mitochondrial DNA damage surveillance," Biochimica et Biophysica Acta, vol. 1833, no. 12, pp. 2943-2952, 2013.

[137] J. Cao, Y. Liu, L. Jia et al., "Curcumin induces apoptosis through mitochondrial hyperpolarization and mtDNA damage in human hepatoma G2 cells," Free Radical Biology and Medicine, vol. 43, no. 6, pp. 968-975, 2007.

[138] L. Liu, W. Zhang, L. Wang et al., "Curcumin prevents cerebral ischemia reperfusion injury via increase of mitochondrial biogenesis," Neurochemical Research, vol. 39, no. 7, pp. 1322-1331, 2014.

[139] L. Li, B. B. Aggarwal, S. Shishodia, J. Abbruzzese, and R. Kurzrock, "Nuclear factor- $\kappa \mathrm{B}$ and $\mathrm{I} \kappa \mathrm{B}$ are constitutively active in human pancreatic cells, and their down-regulation by curcumin (diferuloylmethane) is associated with the suppression of proliferation and the induction of apoptosis," Cancer, vol. 101, no. 10, pp. 2351-2362, 2004.

[140] J. L. Watson, R. Hill, P. B. Yaffe et al., "Curcumin causes superoxide anion production and p53-independent apoptosis in human colon cancer cells," Cancer Letters, vol. 297, no. 1, pp. 1-8, 2010.

[141] D. Morin, S. Barthélémy, R. Zini, S. Labidalle, and J.-P. Tillement, "Curcumin induces the mitochondrial permeability transition pore mediated by membrane protein thiol oxidation," FEBS Letters, vol. 495, no. 1-2, pp. 131-136, 2001. 
[142] S. Karmakar, N. L. Banik, S. J. Patel, and S. K. Ray, "Curcumin activated both receptor-mediated and mitochondria-mediated proteolytic pathways for apoptosis in human glioblastoma T98G cells," Neuroscience Letters, vol. 407, no. 1, pp. 53-58, 2006.

[143] R. Gogada, M. Amadori, H. Zhang et al., "Curcumin induces Apaf-1-dependent, p21-mediated caspase activation and apoptosis," Cell Cycle, vol. 10, no. 23, pp. 4128-4137, 2011.

[144] N. R. Jana, P. Dikshit, A. Goswami, and N. Nukina, "Inhibition of proteasomal function by curcumin induces apoptosis through mitochondrial pathway," Journal of Biological Chemistry, vol. 279, no. 12, pp. 11680-11685, 2004.

[145] T. Choudhuri, S. Pal, M. L. Agwarwal, T. Das, and G. Sa, "Curcumin induces apoptosis in human breast cancer cells through p53-dependent Bax induction," FEBS Letters, vol. 512, no. 1-3, pp. 334-340, 2002.

[146] R. Rashmi, S. Kumar, and D. Karunagaran, "Human colon cancer cells lacking Bax resist curcumin-induced apoptosis and Bax requirement is dispensable with ectopic expression of Smac or downregulation of Bcl-XL," Carcinogenesis, vol. 26, no. 4, pp. 713-723, 2005.

[147] S. Shankar and R. K. Srivastava, "Bax and Bak genes are essential for maximum apoptotic response by curcumin, a polyphenolic compound and cancer chemopreventive agent derived from turmeric, Curcuma longa," Carcinogenesis, vol. 28, no. 6, pp. 1277-1286, 2007.

[148] A. C. Bharti, N. Donato, S. Singh, and B. B. Aggarwal, "Curcumin (diferuloylmethane) down-regulates the constitutive activation of nuclear factor $-\kappa \mathrm{B}$ and $\mathrm{I} \kappa \mathrm{B} \alpha$ kinase in human multiple myeloma cells, leading to suppression of proliferation and induction of apoptosis," Blood, vol. 101, no. 3, pp. 1053-1062, 2003.

[149] R. M. Anson and V. A. Bohr, "Mitochondria, oxidative DNA damage, and aging," Journal of the American Aging Association, vol. 23, no. 4, pp. 199-218, 2000.

[150] S. Judge, Y. M. Jang, A. Smith, T. Hagen, and C. Leeuwenburgh, "Age-associated increases in oxidative stress and antioxidant enzyme activities in cardiac interfibrillar mitochondria: implications for the mitochondrial theory of aging," The FASEB Journal, vol. 19, no. 3, pp. 419-421, 2005.

[151] N. J. Linford, S. E. Schriner, and P. S. Rabinovitch, "Oxidative damage and aging: spotlight on mitochondria," Cancer Research, vol. 66, no. 5, pp. 2497-2499, 2006.

[152] M. López-Torres, R. Gredilla, A. Sanz, and G. Barja, "Influence of aging and long-term caloric restriction on oxygen radical generation and oxidative DNA damage in rat liver mitochondria," Free Radical Biology and Medicine, vol. 32, no. 9, pp. 882889, 2002.

[153] Z. Ungvari, N. Labinskyy, S. Gupte, P. N. Chander, J. G. Edwards, and A. Csiszar, "Dysregulation of mitochondrial biogenesis in vascular endothelial and smooth muscle cells of aged rats," American Journal of Physiology-Heart and Circulatory Physiology, vol. 294, no. 5, pp. H2121-H2128, 2008.

[154] J. J. Smith, R. D. Kenney, D. J. Gagne et al., "Small molecule activators of SIRT1 replicate signaling pathways triggered by calorie restriction in vivo," BMC Systems Biology, vol. 3, article 31, 2009.

[155] M. G. Novelle, D. Wahl, C. Diéguez, M. Bernier, and R. de Cabo, "Resveratrol supplementation: where are we now and where should we go?” Ageing Research Reviews, vol. 21, pp. 1-15, 2015.
[156] I. Sadowska-Bartosz and G. Bartosz, "Effect of antioxidants supplementation on aging and longevity," BioMed Research International, vol. 2014, Article ID 404680, 17 pages, 2014.

[157] J. Marchal, F. Pifferi, and F. Aujard, "Resveratrol in mammals: effects on aging biomarkers, age-related diseases, and life span," Annals of the New York Academy of Sciences, vol. 1290, no. 1, pp. 67-73, 2013. 


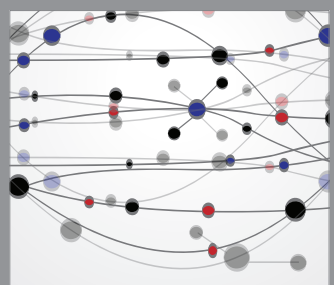

The Scientific World Journal
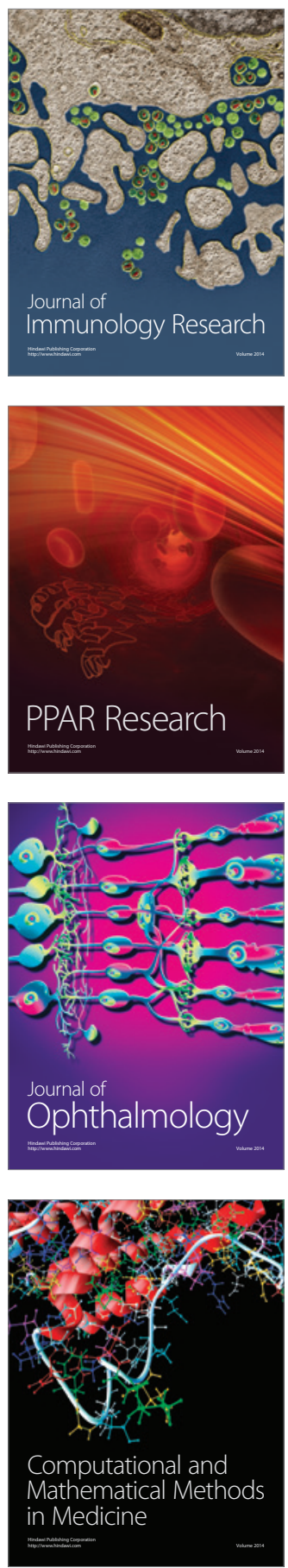

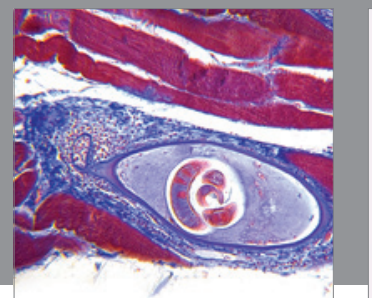

Gastroenterology

Research and Practice
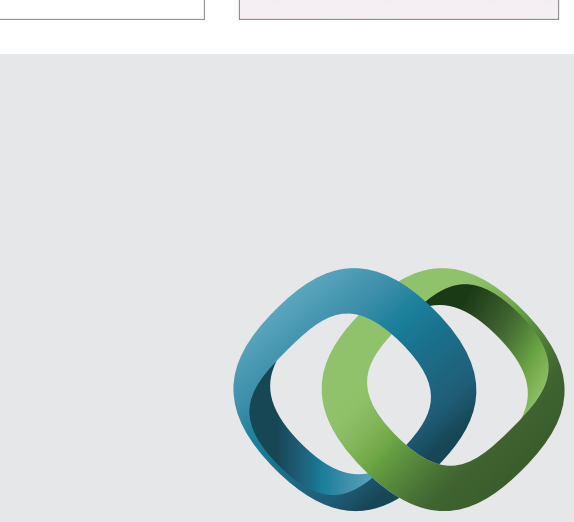

\section{Hindawi}

Submit your manuscripts at

http://www.hindawi.com
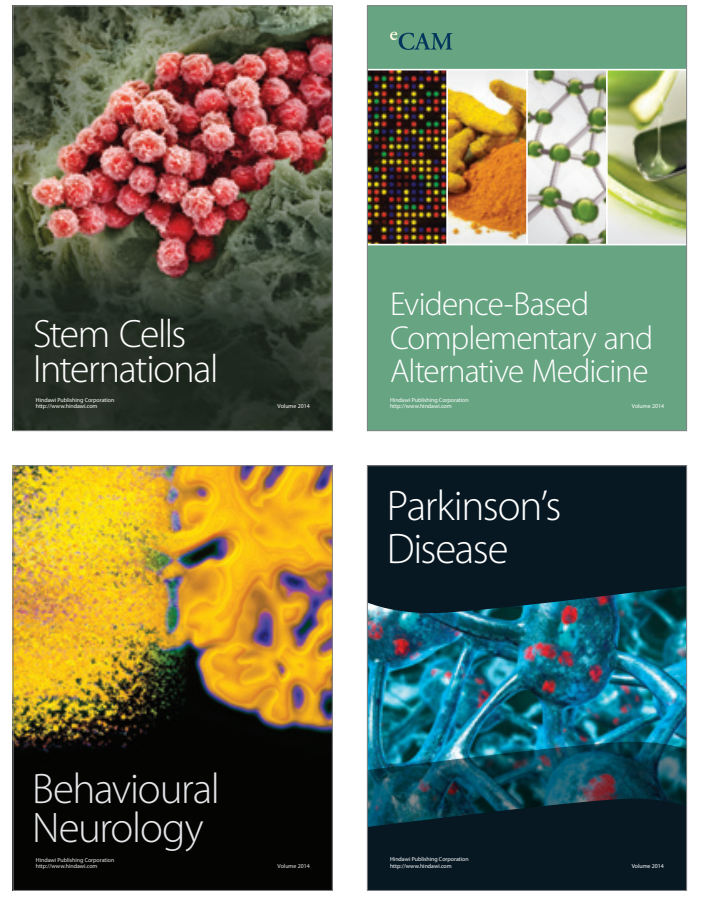
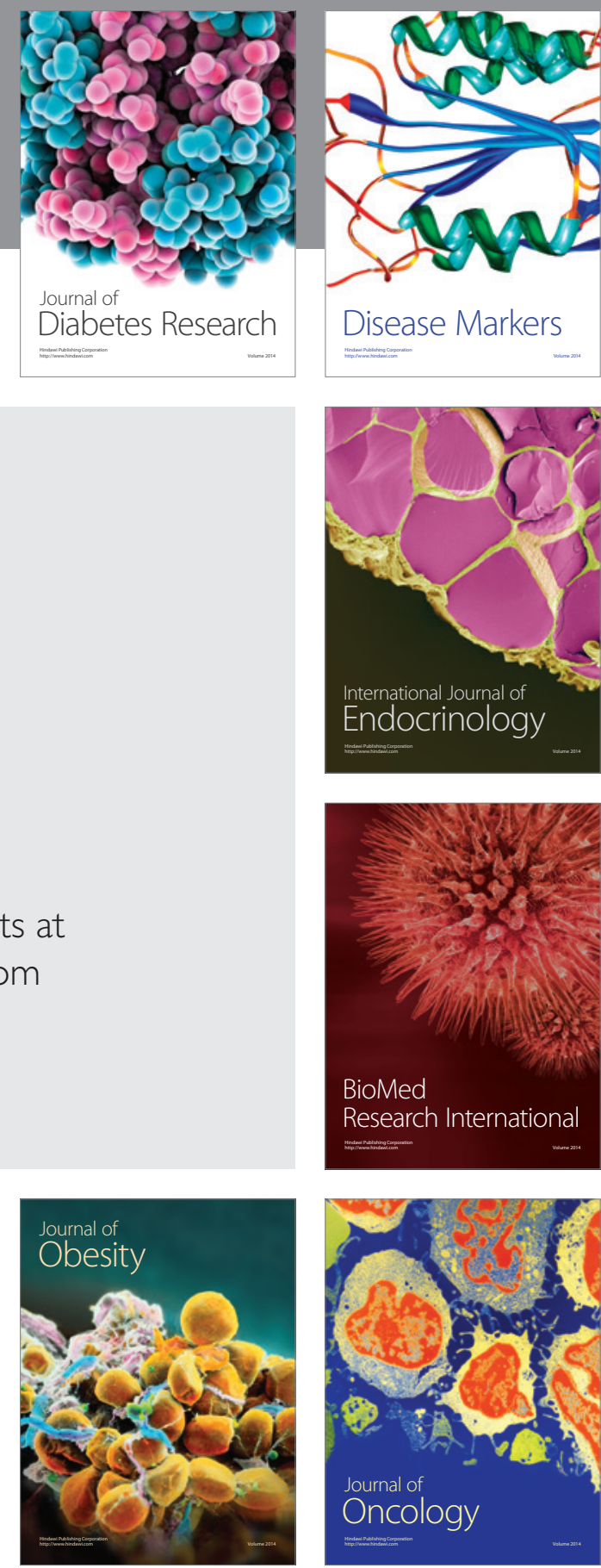

Disease Markers
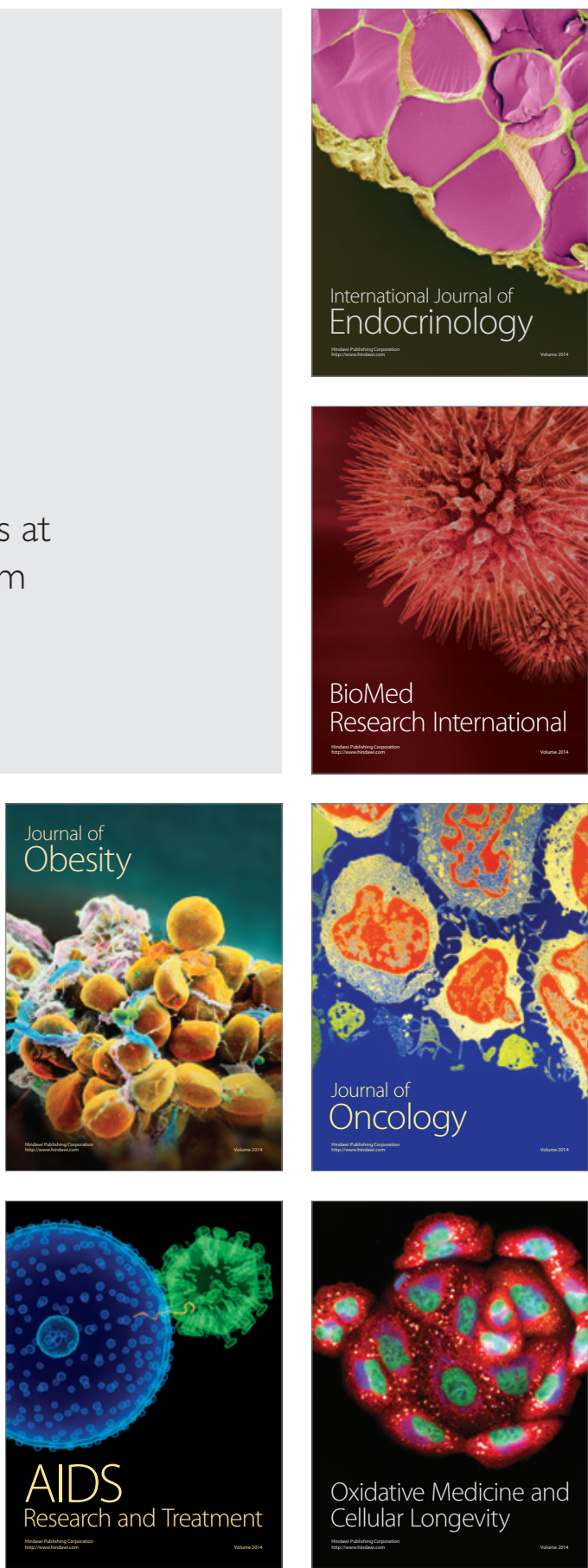